\title{
Erratum to: Patterns and trends in coral reef macroalgae browsing: a review of browsing herbivorous fishes of the Indo-Pacific
}

\author{
Laura D. Puk • Sebastian C. A. Ferse • \\ Christian Wild
}

Published online: 18 July 2016

(C) Springer International Publishing Switzerland 2016

\section{Erratum to: Rev Fish Biol Fisheries (2016) 26:53-70 DOI 10.1007/s11160-015-9412-Z}

Unfortunately, the footnote of Table 1 has been missed in the original publication of the article.

Table 1 along with footnote and the one of the references has been corrected in this erratum.

The online version of the original article can be found under doi:10.1007/s11160-015-9412-z.

L. D. Puk $(\bowtie) \cdot$ C. Wild

Marine Ecology, Faculty of Biology and Chemistry

(FB2), University of Bremen, P.O. Box 3304 40,

28334 Bremen, Germany

e-mail: puk.laura@googlemail.com

S. C. A. Ferse

Leibniz Center for Tropical Marine Ecology (ZMT)

GmbH, Fahrenheitsstr. 6, 28359 Bremen, Germany 


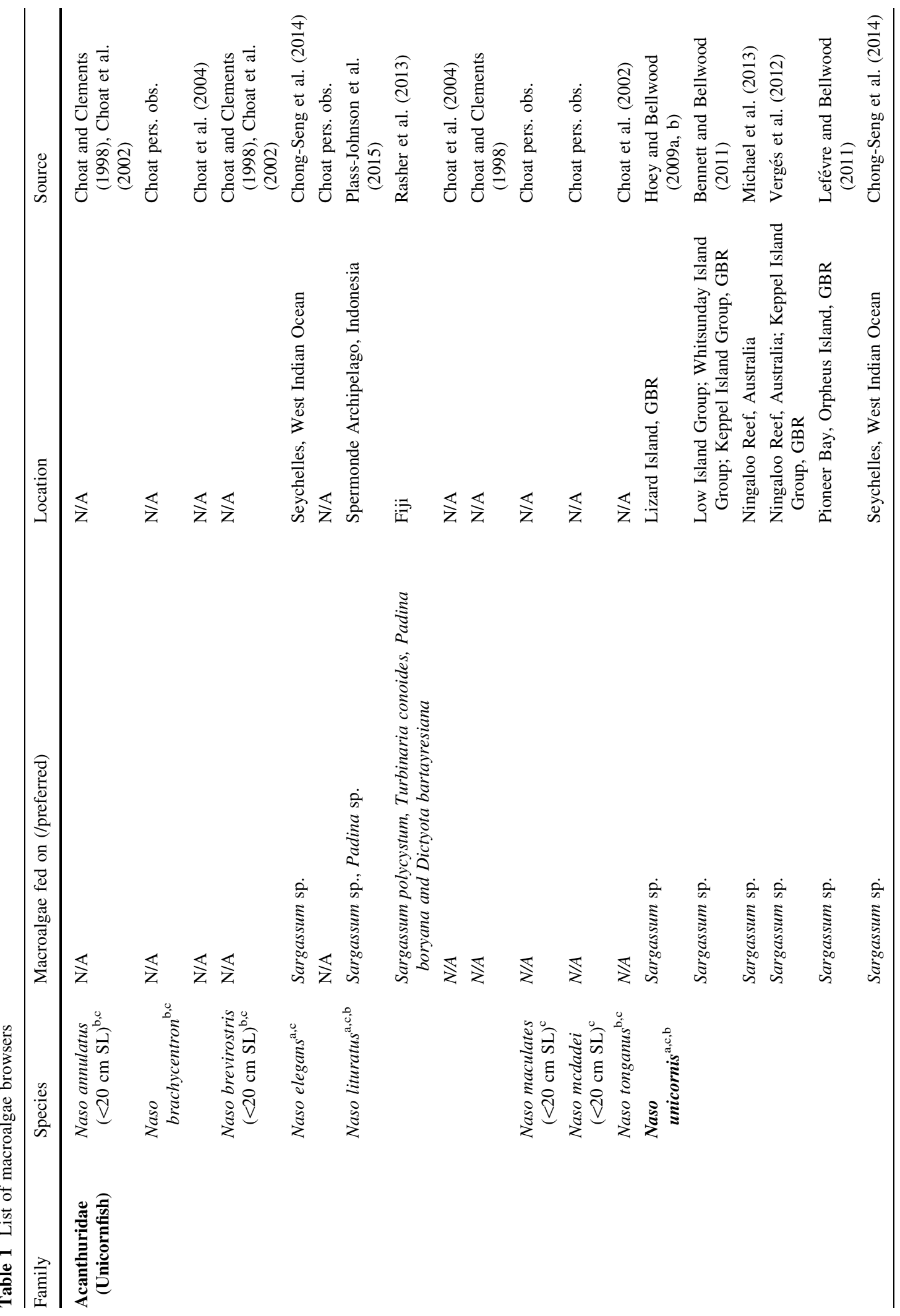




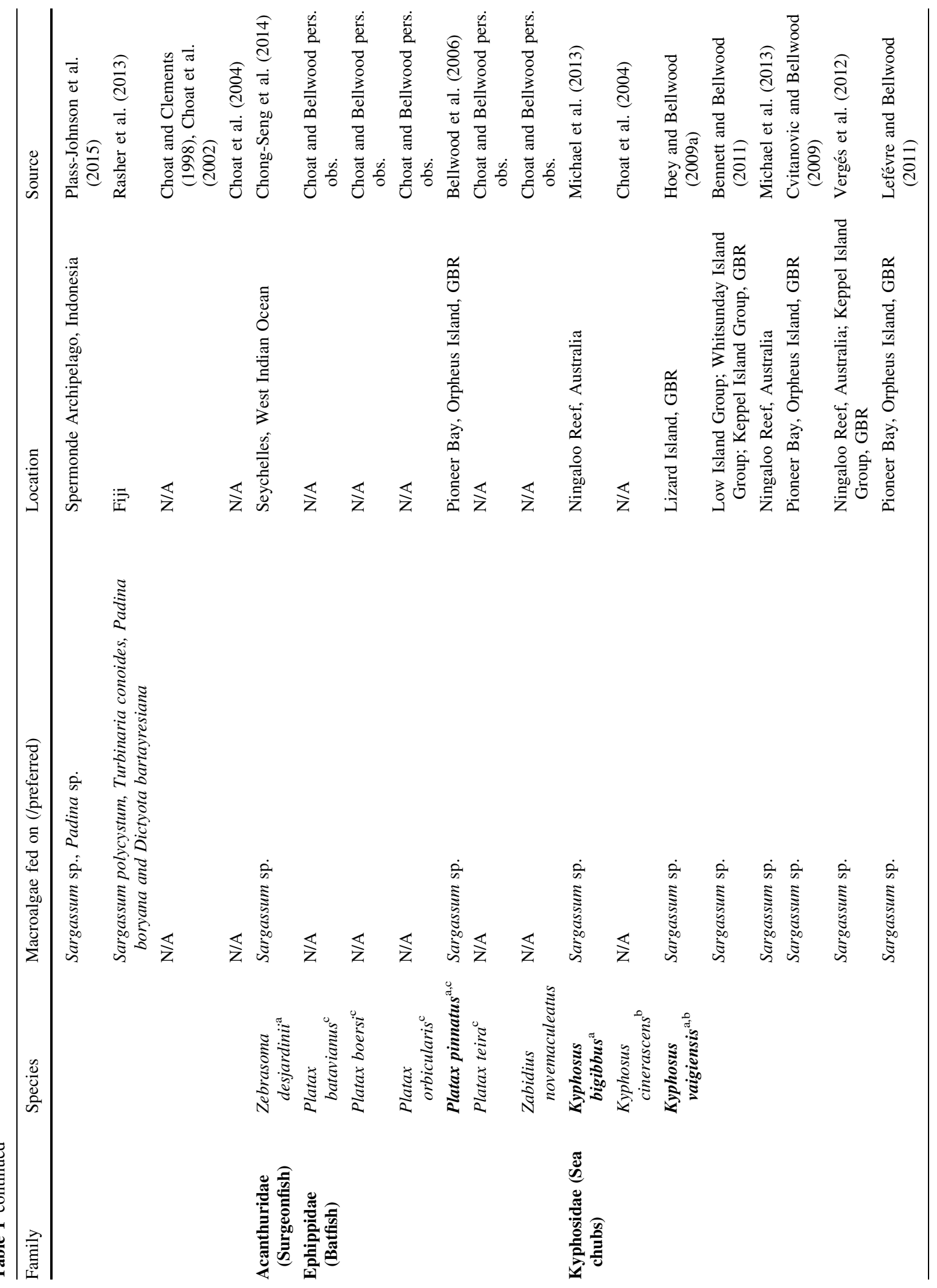




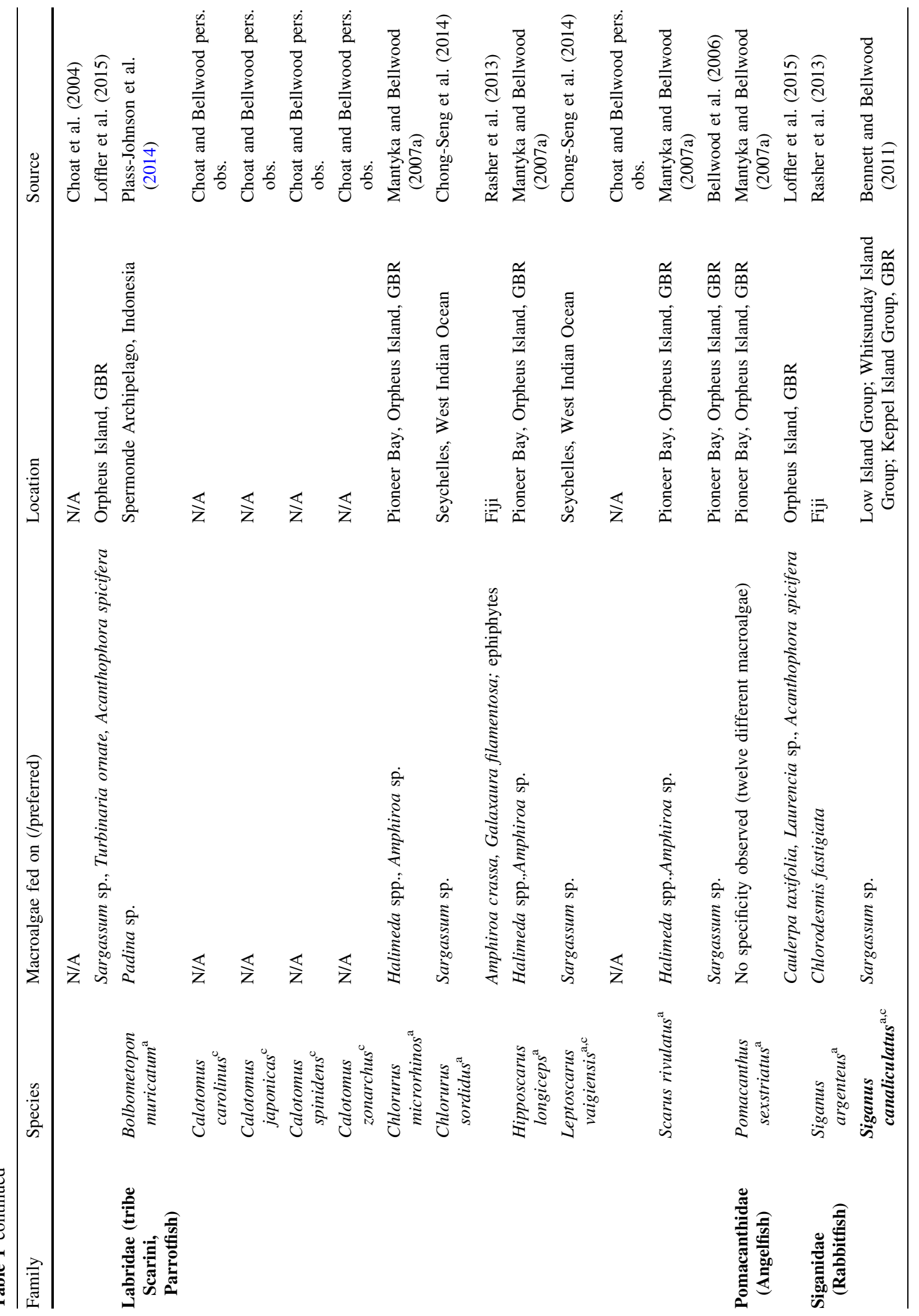




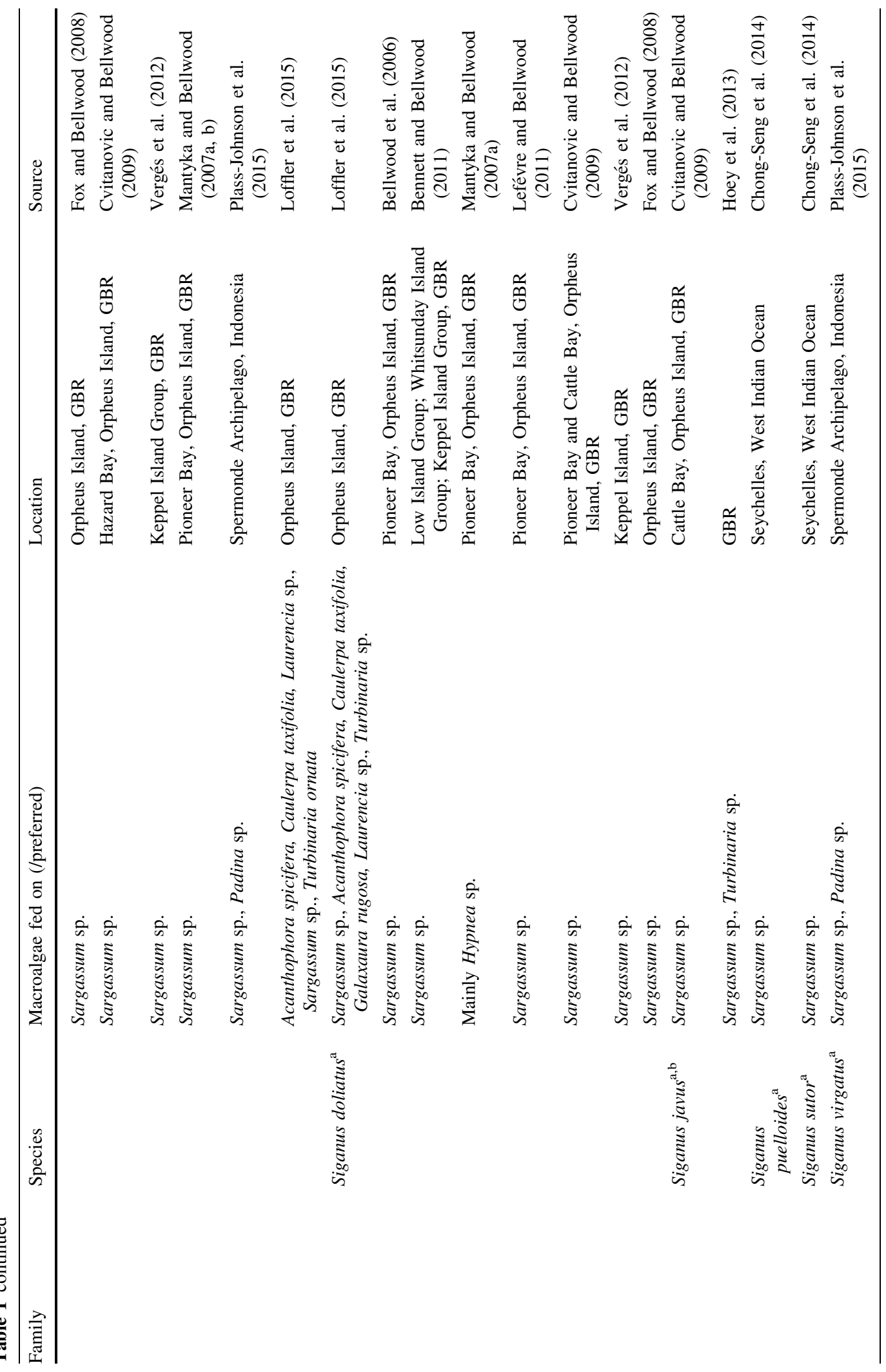




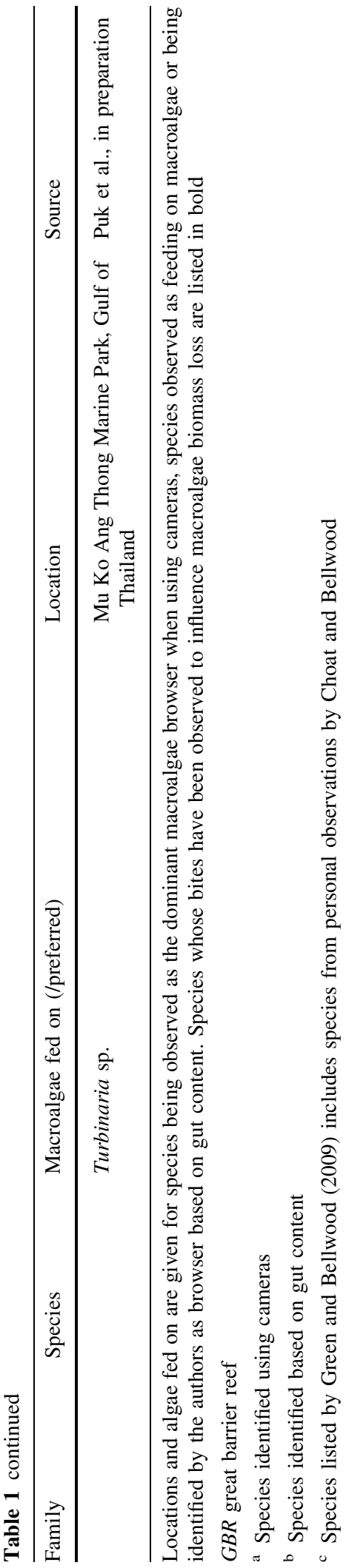

\section{References}

Plass-Johnson J, Ferse SCA, Wild C, Teichberg M (2014) Observation of macroalgal browsing in juvenile humphead parrotfish, Bolbometopon muricatum in the Spermonde Archipelago, Indonesia. Bull Mar Sci 90:763-764. doi:10. 5343/bms.2014.1006

\section{Springer}

